\title{
Understanding productivity effects of hydraulic fracturing in unconventional natural gas deposits and implications for adoption in the developing world
}

\author{
Timothy Fitzgerald, ${ }^{1}$ and Charles F. Mason ${ }^{2 *}$ (D) \\ ${ }^{1}$ Rawls College of Business, Texas Tech University, Lubbock, TX, USA and ${ }^{2}$ Department of Economics \& \\ Finance, University of Wyoming, Laramie, WY, USA \\ *Corresponding author. E-mail: bambuzlr@uwyo.edu
}

(Submitted 14 October 2019; revised 15 April 2020, 15 August 2020; accepted 18 October 2020; first published online 8 January 2021)

\begin{abstract}
Hydraulic fracturing (HF) has transformed the North American oil and gas industry, leading to increased consumer surplus and reduced carbon emissions. While HF may have similar potential for the developing world, adoption has been limited to date, plausibly because of perceptions of potential local costs and the need to develop technical proficiency. We empirically evaluate the incremental contribution of HF in the United States. We find considerable evidence of differences in application and productivity across operating firms and vertical pairings of firms, suggesting intellectual property and learning by doing may both play important roles. At the same time, secrecy regarding the chemical composition of fluids used in $\mathrm{HF}$ is a potential deterrent to its application for fear of local costs. Developing countries must accommodate these characteristics if adoption of HF is to help meet energy demands and achieve climate policy goals.
\end{abstract}

Keywords: hydraulic fracturing; innovation; natural gas; oilfield service companies; toxicity; trade secrets JEL classification: L71; O13; Q35; Q53

\section{Introduction}

Hydraulic fracturing (HF) has transformed the North American oil and gas industry and, by extension, the global natural gas market (Rogers, 2011; Yergin, 2011; Jacoby et al., 2012; Hefner, 2014). Increased natural gas production in the United States (US) has had important impacts on markets, generating benefits to consumers and producers alike (Mason et al., 2015; Hausman and Kellogg, 2016). This transformation induced a reduction in the use of coal for power generation, thereby lowering greenhouse gas emissions (Fell and Kaffine, 2018). Energy supply outside the developed world, where coal currently has a 36 per cent share of primary energy and is not falling as fast as in developed countries, might enjoy similar benefits (BP, 2019). Promoting development 
of local resources may be needed to increase adoption and capture the climate benefits. ${ }^{1}$ Yet the addition of unconventional resources to the reserve base has largely been limited to the US and Canada, even though the developing world holds the lion's share of current proved reserves (Gamper-Rabindran, 2018; BP, 2019). HF has proven to be controversial in a number of political jurisdictions. Gomes and Brandt (2016) identify several external effects that might explain hesitancy to adopt $\mathrm{HF}$, including land use footprint, large scale water usage, possible water contamination, wastewater disposal, air emissions and sound pollution. Of these, concerns regarding potential water contamination are particularly noteworthy (Hull, 2014).

Some jurisdictions have responded to these concerns by banning HF, others by requiring that the chemical injectants used in the frac process be reported and in some cases disclosed. The first state to require such reporting was Wyoming. Like many states that followed, the Wyoming regulation allowed for firms to withhold information if they felt that revelation would cause the firm commercial harm; in such an event, the firm could claim the injectant represented a 'trade secret.' Even so, Wyoming's role as an early regulator provides a unique opportunity to study the role played by the various chemicals in the natural gas 'production function,' as well as the importance of toxicity of such chemicals and the transparency - or lack thereof - in the reporting process. We take up this opportunity in the analysis in this paper.

Our empirical study is novel. We estimate a production function for HF using data from wells drilled in Sublette County, Wyoming regarding the specific ingredients in the fracturing fluid that are injected down the wellbore, as well as the well orientation. ${ }^{2} \mathrm{We}$ estimate the marginal productivity of HF, identify how productivity changes over time, and the role of participating firms. Productivity can be measured in terms of the targeted natural gas and oil. We expect that the marginal productivities have changed with more experience - although because we observe incomplete production histories due to continuing activity, our analysis is limited to the early stages of a well's life. Deployment of $\mathrm{HF}$ also leads to flowback of injected water, along with highly saline groundwater; these by-products can contain toxic ingredients that are an important environmental concern about the process.

We consider the relationships between operating and servicing firms, who together create essential intellectual capital that is used to unlock unconventional natural gas. Fracturing technology has been developed through 'learning by doing,' which our data allow us to observe. We quantify the contribution of HF to well productivity, in particular focusing on the productivity effects associated with various additives to injected fluid; we identify three different types of impacts. First, we observe how the physical characteristics of frac jobs change over our sample period, in terms of both scale and scope. This

\footnotetext{
${ }^{1}$ These benefits depend in part on the potential to substitute natural gas for coal in the generation of electricity, which in turn depends on the pre-existing level of coal usage. This usage varies across countries; for example, Argentina uses relatively little coal. In such a setting, benefits from increased production of natural gas will be linked to switching from fuel oil to natural gas, which would then generate smaller reductions in $\mathrm{CO}_{2}$ emissions, or via increased exports, which entail larger distribution costs. In either event, net benefits from expanded production of natural gas would be smaller.

${ }^{2}$ In our sample, wells are commonly vertically or directionally drilled. In other settings, HF is often associated with horizontally drilled wells - where the well is drilled vertically to a predetermined depth, after which the well-bore executes a right-angle turn and drilling continues parallel to the surface. Vertical wells are drilled straight down into the earth. Directional wells are in between, with a non-vertical portion or a less acute turn below the surface.
} 
includes such simple tradeoffs as the amount of water used in a frac versus the required additives to carry additional sand in the injected slurry. Second, we observe how firm behavior changes over the course of time - specifically, regarding the decision to withhold disclosure of certain ingredients they use in a particular job. We are also able to objectively assess the productivity of wells with differing levels of disclosure. We find that there are important differences between firms and over time. Third, we observe differing levels of toxicity in various components of the fracturing fluid, and we can assess trends in use of toxic ingredients. Much public concern about environmental risks of HF has focused on the toxicity of injected fluids and produced water, so these results help inform the policy debate. Here again we find large differences across participating firms, and a trend towards increasing toxicity over time. One interpretation of this result is that as demand for more sand in injected slurry has risen, firms must add an increasingly complex and potentially toxic set of additives to maintain performance. But larger frac jobs with more sand allow for more resources to be extracted from a single well.

Our results allow us to back out the impact of various injected materials, and in particular to discuss the potential for substitution between injectants that have the potential to contaminate groundwater and injectants that are relatively benign. In this way, our results provide the backdrop for a deeper discussion of the benefits and costs associated with HF, and can serve as a springboard for a deeper discussion of potential regulatory approaches.

While developing countries are likely to play an important role in meeting global climate goals, they also have their own economic and energy growth objectives. Natural gas is a cleaner fossil fuel alternative to coal or fuel oil. It can also provide potential benefits in terms of facilitating renewable electricity generation, which is subject to significant variability over time (Sinn, 2017). However, relying exclusively on imports from established producers creates energy security and terms of trade concerns and is relatively difficult to transport compared to other fossil fuels. Even so, deposits are widespread, particularly throughout the developing world, which creates a potential alternative source of supply to global markets. For example, exports from Argentina to Chile, Uruguay and Brazil have increased markedly over the last few years; exports of liquified natural gas have also increased (EIA, 2019). This creates an opportunity for developing countries to further their economic, energy, and climate goals by exploiting their own resources. Although the use of HF has the potential to facilitate such an expansion, thus far HF has not been used much in the developing world. Two possible explanations for this sluggish deployment are the need for countries to develop the technological sophistication embodied in HF, and concerns related to potential adverse environmental impacts, in particular the potential for water contamination, in countries that appear to be promising candidates for shale gas development (Mares, 2012, 2013; Dora, 2014; Gomes and Brandt, 2016; Sierra, 2016; Costie et al., 2018; Evensen, 2018).

Based on our empirical results, we draw three lessons for developing countries as they contemplate how to speed adoption of HF and thereby unconventional natural gas production. First, the technology evolves over time through experimentation reliant on substantial intellectual property inputs. Operating and servicing firms bringing technical proficiency to the developing world will likely demand protection of their intellectual contributions. Second, toxic substances that help increase productivity in HF must be considered as part of the technology adoption process. This will require consideration of the interaction between intellectual property and environmental protection, as well as tradeoffs between deployment of HF and local demands for clean water. Third, 
firms differ and interact in potentially strategic ways. Some rely more on trade secret provisions, others less. It may therefore be desirable to offer multiple tenders to allow productivity differences to bear themselves out.

\section{Background}

While often conflated, drilling and HF are separate processes: drilling refers to the entire process of developing a hydrocarbon resource, while HF is a specific part of the process. Fracturing is performed with specialized pressure pumping equipment, usually after the drilling rig is removed. The wellbore is perforated in a target formation. To focus available pumping power on isolated sections of the wellbore, the pressure pumping typically occurs in stages, with each stage focusing on a portion of the perforated wellbore. A slurry of base fluid (usually water), proppant (often sand), and chemical additives is mixed on the surface. The pressure pumps then force the slurry into the target area, creating complex fractures in the hydrocarbon-bearing substrata. As pressure is reduced, proppant remains in the fractures, leaving a pathway for oil and gas to migrate to the wellbore and then to the surface. Oil and gas molecules that would otherwise be trapped underground can thereby be brought to the surface. ${ }^{3}$

Each frac job has many variables: the amounts of water and sand, the maximum pressures and duration of pumping, and the combination of additives to the injected fluid, which may have a particular recipe. Additives are intended to enhance performance of the fluid in one or more dimensions, for example by reducing friction or increasing viscosity. ${ }^{4}$ The recipes for injected ingredients are viewed as important proprietary assets, especially by service companies. Service companies advertise various recipes and consulting expertise to operating firms.

A substantial technical literature addresses aspects of fracture design and implementation. We focus on two stylized facts: first, that fracture designs continue to evolve. Patel et al. (2014) compares the time trends in frac fluid and proppant design in the Marcellus, Bakken, and Denver-Julesburg basins in the US. In each of these locations, firms have continued to experiment with alternative proppants and worked to increase the amount of proppant delivered. Second, that alternative fluid configurations are used in different areas. This makes cross-sectional analysis of fracturing fluid difficult. What works in the Marcellus may be totally inappropriate in the Bakken. This leads us to focus on a single geographic area, where we use relatively small variation in fracturing fluids and designs to identify differences in production. More importantly, both of these stylized facts have important implications for the propagation of HF and unconventional natural gas development more generally. ${ }^{5}$

Fetter et al. (2018) uses regulatory disclosure data from Pennsylvania to document the diffusion of the most productive frac recipes to other firms, and an attendant reduction in new experimentation that was previously led by the most productive firms. This poses

\footnotetext{
${ }^{3}$ Gold (2014) is a non-technical discussion of the emergence of the HF technology in conjunction with horizontal drilling as a method for enhancing hydrocarbon production from low permeability reservoirs.

${ }^{4}$ Reducing friction allows more fluid to be pumped for a given pressure, while higher viscosity allows more proppant to be carried in a fixed amount of fluid.

${ }^{5}$ Because of potential geologic differences, it is plausible that specific combinations of ingredients that work in Wyoming, the area we use for our analysis, may not work as well - or at all - in other regions. Even so, our results, in particular regarding behavior of firms involved in HF in our area of study, may offer useful lessons for other regions.
} 
a tradeoff for regulators: requiring disclosure of chemical additives to assuage environmental concerns allows other firms to imitate the most productive firms in the sector, but also curtails innovation by those same firms. A regulatory scheme that mandates disclosure or compromises the productivity gains that firms capture by experimenting with frac recipes could undermine the viability of unconventional resources. On the other hand, excessive secrecy may exacerbate fears about environmental degradation even as productivity gains could be realized.

The widespread endowment of natural gas deposits that could be exploited with HF creates an opportunity for countries across the developing world. Natural gas resources, particularly unconventional resources that will likely require fracturing, are abundant throughout the developing world (Weijermars et al., 2011; Bocora, 2012; Wang et al., 2016; Evensen, 2018). However, it is important to recognize that continual improvement and modification are commonplace, as the design and application of frac jobs is adjusted to best suit the particular geology. Specific countries where HF is thought to have the potential to greatly increase production include Argentina (Mares 2014a, 2014b, 2014c, Gomes and Brandt, 2016; Sierra, 2016; Florencia, 2018), Brazil (Dora, 2014), China (Lin, 2018), Mexico (Mares, 2012), and South Africa (Morkel and de Witt, 2018).

Argentina is a particularly noteworthy example, as it is believed to possess the secondlargest shale gas deposits and fourth-largest shale oil deposits in the world (Mares, 2014b; Sierra, 2016). Interest in Argentina's shale resources has been strong following a significant shale resource discovery in 2011 by Yacimientos Petrolíferos Fiscales (YPF), the national oil company. Much of this interest has been expressed by oil and gas majors like Chevron, ExxonMobil, Shell, and Total (Mares 2014a, 2014b; Costie et al., 2018). Particularly important is the Vaca Muerta deposit, which has been referred to as the 'crown jewel' of Argentina's shale resources (Gomes and Brandt, 2016). In 2013, the Argentine government revised its oil and gas regulations to attract investment (Mares, 2014c) in order to promote development of its shale resources (as well as some conventional deposits). Development of Vaca Muerta began in earnest not long after, starting with an accord signed between Chevron and YPF, and ratified by the local government (Costie et al., 2018). Despite these reforms, chronic national policy uncertainty works against development of Argentina's resources (Mares, 2013, 2014b, 2014c; Gomes and Brandt, 2016).

Development of the Vaca Muerta shale deposit seems to present an intriguing example of the tension between the potential benefits from expanded production and the possible costs of development, which are thought likely to fall on citizens near the zone of development. Environmental concerns have also been expressed. Mares (2012) notes a 'growing NGO movement in the country that is focusing on HF issues.' Similarly, Sierra (2016) opines that environmental groups and local communities are likely to oppose HF until the government establishes a suitable regulatory framework for unconventional production; Gomes and Brandt (2016) makes a similar point. Relatedly, Costie et al. (2018) argue that 'antifracking coalition members responded to the [ChevronYPF] accord by becoming considerably more active.' One argument for the strength of such opposition is the belief that understanding of the risks associated with HF is weak. Indeed, Mares (2013) argues that such 'environmental concerns will slow shale gas development in Argentina.' A key goal of our analysis is to offer greater clarity of some of the key aspects of unconventional resource development.

Mexico provides another example of potential gains from broader adoption of HF. Decline has overtaken replacement of Mexican oil and gas production (BP, 2019), even 
as pipeline imports of natural gas from the US increase. Some of this gas is produced from the Eagle Ford shale in South Texas, a formation that is thought to extend south across the border, but which has not yet been commercially exploited. Following recent energy sector reforms, the Burgos Basin, which encompasses the Eagle Ford resources, has been opened to private investment in a tacit admission that the national oil company Petròleos Mexicano (PEMEX) has not been able to easily tap those resources on its own.

In addition to the technical considerations associated with grafting the HF technology onto a new geologic setting, there are important concerns regarding the effects of HF on other resources, in particular fresh water. Our study is well positioned to clarify this debate, as we consider technical (productivity) related concerns, institutional (industrial organization) related concerns, and environmental (toxicity) related concerns.

\section{Conceptual framework}

A main focus of our analysis is to determine the role played by various ingredients in an HF process. To that end, we posit a production function that can be described by

$$
\ln (y)=\beta \ln (A)+\gamma \ln (z)+\sum_{i} \alpha_{i} \ln \left(X_{i}\right)
$$

where $y$ is the productivity measure of interest, $z$ is the footage of the wellbore that is treated by $\mathrm{HF}, X_{i}, i=1, \ldots, n$, is an ingredient used in the frac job (measured as volume of ingredient per foot treated), and $A$ is a well-specific productivity parameter. We assume $\ln (A)$ is a linear combination of the elapsed time since the well was drilled, AGE, the total volume injected in the well per foot treated, SIZE, and the ratio of proppant (typically sand) to water injected, SANDRATIO (Covert, 2014).

The data we use lists scores of additives; to facilitate the empirical analysis we aggregate into six categories: biocides, breakers and crosslinkers, chemical additives, gelling and foaming agents, surfactants, and all other ingredients. Table A1 in the online appendix summarizes the six classes of additives with examples.

As operators compete in competitive output markets, they have a choice of differentiated completion inputs provided by different service companies. One argument for product differentiation among service companies is to relax pressures to compete on price; to the extent that service companies disguise their respective product mixes, they are able to enhance market power. ${ }^{6}$ Anecdotally, service companies are able to price discriminate, which implies that product differentiation should be greatest to support this outcome. Service companies could differentiate their products in a number of ways, but adjusting the frac recipe is one obvious mechanism.

\section{Data}

Our analysis relies on data drawn from four sources. First, we use well-specific records extracted from the FracFocus repository to document what was injected into each wellbore during the well completion process. FracFocus is a joint venture of the Interstate Oil and Gas Compact Commission and Groundwater Protection Council (see their site at

\footnotetext{
${ }^{6}$ The basic idea is that incomplete information about firms' characteristics, or the products they provide, allows them to allege they are different - and presumably better - at some facet of the business. To the extent they are able to convincingly claim they are unique, they procure something like market power. See Carlton and Perloff (2008) for discussion.
} 
http://www.fracfocus.org). Since 2010, FracFocus has published company-provided data on HF jobs across the country. In some states, FracFocus has satisfied state-level disclosure regulations; in Wyoming, the Wyoming Oil and Gas Conservation Commission (WOGCC) - the primary regulator of oil and gas operations in the state - maintains a similar but separate registry for legal disclosure purposes that is not available to the public. In Wyoming, all wells with drilling permits issued after August 17, 2010 were subject to disclosure. ${ }^{7}$ The FracFocus database has been revised through three versions, and we use data from each version because wells were drilled and reported at varying times as the database evolved. ${ }^{8}$ The information disclosed in each version of the FracFocus database has changed slightly, so we were careful to extract similar information from all versions.

Second, we used completion reports (Form 3) from the WOGCC to augment the FracFocus data with additional information about the frac jobs. The completion reports allowed us to cross-validate the FracFocus data on injected substances, as well as add information about technical aspects of each frac job. Operators are required to file Form 3 with the WOGCC after a well is completed and each time a well is recompleted. We dropped all wells with recompletions from our production analysis, but kept them for toxicity analysis. ${ }^{9}$ Appended to these reports is detailed information about frac design and implementation. We use these data to characterize technical aspects of the completion, including the number of stages and the footage of the treated interval.

Third, we matched the specific injectant data from FracFocus to information about toxicity of the substances using the Occupational Safety and Health Administration (OSHA) Occupational Safety Database. This allows us to comment on the potential for environmental spillovers. The OSHA Occupational Chemical Database (available at https://www.osha.gov/chemicaldata/) includes 751 chemical compounds that are considered potentially hazardous. The database was originally compiled in cooperation with the Environmental Protection Agency. Compounds are indexed by unique chemical abstract service (CAS) numbers. Because these same unique identifiers are reported in FracFocus records, we are able to match the compounds directly. The database also reports exposure guidelines. In cases where we were unsure about a compound, we referred to the National Institute for Occupational Safety and Health pocket guide to clarify. Despite this cross-referencing, there were numerous compounds that we were not able to identify by reported name or CAS number. Our maintained assumption is that any such compounds are not toxic hazards. ${ }^{10}$

Fourth, we used production reported at the well-month level to assess the ultimate production of alternative approaches to HF. These data were compiled by private data provider Enverus (www.enverus.com). These data are derived from operator reports of well-level production. Production can be aggregated in several different ways. In our preliminary results, we use aggregate production over the first 6 or 12 months of a well's

\footnotetext{
${ }^{7}$ If firms value avoiding disclosure, a natural concern is that firms timed permit application for approval before the policy went into place. This does not appear to be the case. The modal day for permit approval in all of 2010 was August 18, the day after the policy went into effect.

${ }^{8}$ EPA (2015) provided a detailed analysis of the first version of the database.

${ }^{9}$ Because we dropped all wells with recompletions, including the initial completion of such wells, this resulted in dropping nearly all wells from one operator.

${ }^{10}$ Because operators can elect not to disclose the CAS number of certain additives that they deem are proprietary business information, we are unable to assess the toxicity of undisclosed additives. We conduct separate analyses along this dimension.
} 
life. We acknowledge that some elements of frac design may be targeted at increasing peak flow, or maintaining higher flow rates over time. We also used monthly data to estimate a panel model of well performance.

One of the most important production basins in Wyoming lies in Sublette County (figure A1 in the online appendix). Oil and gas have been part of the landscape there since 1939, when the first well was drilled there (though the well was plugged and abandoned after it found natural gas, as opposed to oil). By the early 1990s, advances in exploitation of western tight sands made the geology of Sublette County more attractive. HF of vertical wells was common at this point in time, although the designs were far different and smaller in scale than more recent application of the technology that we investigate. Production of both oil and natural gas expanded rapidly during the first years of the 2000s. ${ }^{11}$

An overwhelming majority of the wells in Sublette County are located on federal surface and minerals, and are therefore subject to federal environmental oversight as administered by the Bureau of Land Management (BLM). A very small fraction of wells are located on private minerals, with the balance on state-owned surface and minerals. All these wells are subject to environmental regulation by the state of Wyoming. During the period we study, federal agencies had no rules pertaining directly to HF, so state rules covered both.

We have detailed completion and production information from 569 wells in Sublette County, of which 297 wells have information from both FracFocus and WOGCC completion reports and have not been fractured more than once. Our sample is primarily drawn from two adjacent western tight sands plays that share a common leasing and well-servicing market.

As operators hire service companies to fracture, both parties may experience gains from learning-by-doing. Contemporaneously, firms may observe other experiments and tweak their own HF formulae to increase production. A listing of variables used in our analysis, along with their units of measurement, is contained in table A2, while table A3 provides summary statistics for frac jobs in our sample (see the online appendix). A wide range of frac designs are used, with an order of magnitude separating the smallest from the largest completions in our sample as measured by injected water volume. Similarly, an order of magnitude separates the lightest fracs (lowest sand/water ratio) from the highest. Suspending a greater quantity of proppant in a fixed amount of fluid requires increasingly sophisticated fluid chemistry.

An important question we address is: how common is it for additives to be withheld as confidential business information, or trade secrets? Table 1 summarizes the use of trade secret provisions across the categories of fluid additives. To simplify the complexity of frac fluids with dozens of ingredients, we use categories of additives characterized by purpose in Stringfellow et al. (2014). Many of the ingredients that we see in injection reports do not match with compounds analyzed by Stringfellow et al. (2014), and we therefore have a difficult time categorizing them. For compounds that we observed in other wells, we used the modal purpose in the other data to help classify ingredients by purpose. Nonetheless, we have many unclassified additives. The unclassified category

\footnotetext{
${ }^{11}$ However, expansion of production in Sublette County was affected by its remote location: as production increased, insufficient infrastructure was in place to transport natural gas to markets, both locally and over a longer distance (Oliver et al., 2014).
} 
Table 1. Count of ingredients per frac job withheld as trade secrets

\begin{tabular}{lcccc}
\hline & Mean & Std. Dev. & Min & Max \\
\hline Additive & 3.9 & 3.0 & 1 & 13 \\
\hline Biocide & 2.4 & 2.9 & 0 & 10 \\
\hline Breaker & 4.8 & 2.9 & 0 & 12 \\
\hline Gel & 2.3 & 1.3 & 1 & 6 \\
\hline Slicks & 2.6 & 1.1 & 0 & 5 \\
\hline Unspecified & 64.8 & 16.1 & 12 & 84 \\
\hline Total & 84.3 & 11.8 & 28 & 90 \\
\hline
\end{tabular}

Notes: Data compiled from FracFocus records. $N=297$. Total includes undisclosed proppants.

is the most common category for trade secrets, followed by biocides used to control subsurface bacteria. ${ }^{12}$

Well completions occur over a period of four calendar years (2010-2013), which raises the possibility that a trend in claims of secret additives occurred. While we did not find a significant trend over time, we do observe significant differences across firms - both operators and service companies. Disclosure of the fluid ingredients reveals to the public and potential competitors what is in fracturing fluid. The FracFocus records provide information about the concentration of each ingredient in the additive and in the final fluid that is injected. This makes it hard to back out exactly how to mix the fluid and probably contains no information about sequencing or timing of mixing, but provides enough information to expect what concentration of a given additive is likely to be in the fluid (if, for example, an interested person wanted to know what calibration was needed to detect the presence of a particular chemical compound). While ingredients are important, the precise measurement and the practice of how they are combined is at least as important as knowing the identity of each component. The recalcitrance of some firms to reveal the ingredients has exaggerated concerns about the environmental risks associated with those additives.

There is a potential tradeoff between the trade secrecy and disclosure of a CAS number and associated toxicity. Recall that undisclosed additives cannot be assessed for toxicity using our methodology. A firm might have a number of motivations for invoking a trade secret. One reason is that a firm might believe it can maintain an edge in the marketplace by obscuring its particular recipe for HF. Alternatively, a firm might simply be experimenting with a new formula, and wishes to conceal the experiment and its outcome from any potential competitors. Third, and non-exclusively, a particularly toxic additive could be kept out of public scrutiny by protecting it with a confidential label. Weighing the various arguments for and against the disclosure of a particular additive is likely to vary at the firm level, as competitive position and views on corporate liability might vary.

Using our measure of toxicity, table 2 summarizes the number of different additives, by category, that are indicated to have toxicity hazards. As expected from previous studies, two of the most toxic categories of additives are gels and breakers or crosslinkers, which are used to adjust fluid viscosity (upwards for injection, then downwards for fluid

\footnotetext{
${ }^{12}$ We use Kahrilas et al. (2014) to confirm our categorization.
} 
Table 2. Count of toxic ingredients per frac job

\begin{tabular}{llllc}
\hline & Mean & Std. Dev. & Min & Max \\
\hline Additive & 1.8 & 1.0 & 0 & 4 \\
\hline Biocide & 0.0 & 0.0 & 0 & 0 \\
\hline Breaker & 1.9 & 1.5 & 0 & 7 \\
\hline Gel & 1.1 & 0.7 & 0 & 3 \\
\hline Slicks & 0.3 & 0.47 & 0 & 1 \\
\hline Unspecifed & 0.3 & 0.5 & 0 & 3 \\
\hline Total & 7.1 & 3.2 & 2 & 17 \\
\hline
\end{tabular}

Notes: Data compiled from FracFocus records, as matched to OSHA Occupational Safety Database. $N=297$.

recovery). More of a surprise is that proppants are more often matched to toxic substances than many other compounds. Certainly sand and ceramic proppants are not often thought to be the greatest environmental hazard in frac fluid. However, many operators do treat the proppant, such as coating it with resin; and the coating may be in the OSHA database. Chemical additives used to balance $\mathrm{pH}$ or other properties of the fluid, because they are often strong acids, are unsurprisingly also common on the toxic list.

The wells in our sample produce some oil along with the gas, as well as valuable natural gas liquids (figure A2 in the online appendix). For that reason we consider both raw (dehydrated) gas production to identify the main target and total production on a barrel of oil equivalent basis to identify the whole slate of produced compounds. Products are generally not priced on an energy equivalent basis, but the conversion to BOE is useful to consider alternative measures of production. ${ }^{13}$ Here, again, we find large differences in production between the best and worst wells. The connection between production differences and measurable differences in frac inputs is at the core of our productivity analysis.

Because we do not observe sales prices, it is not clear how long an average well must produce before drilling costs are recovered. As mentioned above, large basis differentials for western Wyoming are likely to affect the economic value of production. Firms will balance the the economic value of incremental production from adjusting the frac design or fluid with the cost of those changes. Our analysis falls short of being able to assess the profitability of such input adjustments, both because we do not observe the input costs, but also because we do not observe realized revenues.

The wells in our sample were operated by four firms at the time of completion, one of which has only a handful of the wells that we observe fully. The well completions were provided by three different service companies. In some cases subcontractors assist the primary service company or provide some services that we can observe. For the purposes of our analysis, we focus on the three major service companies, which are likely to have a more substantial role in the overall design of the completion. Table A5 (online appendix) summarizes the frequency of pairings between the operators that we observe and the service companies.

In our estimation sample, service companies $\mathrm{A}$ and $\mathrm{B}$ have roughly equal positions in the local market, each with about 20 per cent of the wells. Company $\mathrm{C}$ has a

\footnotetext{
${ }^{13}$ Table $\mathrm{A} 3$ in the online appendix presents production statistics, while table A4 summarizes production measures.
} 
Table 3. Summary of trade secrets and toxicity, per well by service company and operator

\begin{tabular}{|c|c|c|c|c|c|c|c|c|}
\hline & \multicolumn{4}{|c|}{ Trade secrets } & \multicolumn{4}{|c|}{ Toxic additives } \\
\hline & Mean & Std. Dev. & Min & Max & Mean & Std. Dev. & Min & Max \\
\hline \multicolumn{9}{|c|}{ Service company } \\
\hline A & 1.8 & 1.1 & 0 & 8 & 5.6 & 2.4 & 2 & 15 \\
\hline$B$ & 12.0 & 5.3 & 0 & 16 & 10.4 & 1.7 & 7 & 17 \\
\hline C & 2.6 & 3.3 & 0 & 9 & 6.5 & 3.2 & 2 & 16 \\
\hline \multicolumn{9}{|c|}{ Operator } \\
\hline 1 & 2.6 & 3.2 & 0 & 9 & 7.0 & 3.2 & 2 & 16 \\
\hline II & 12.6 & 4.7 & 1 & 16 & 10.2 & 1.4 & 7 & 13 \\
\hline III & 1.7 & 0.5 & 1 & 2 & 4.7 & 1.5 & 2 & 9 \\
\hline IV & 1.7 & 2.9 & 0 & 5 & 14.3 & 2.3 & 13 & 17 \\
\hline
\end{tabular}

Notes: Data compiled from FracFocus and WOGCC, as matched to OSHA Occupational Safety Database. Total $N=297$.

larger stake of about 45 per cent. There is a similar concentration among the operating firms - with three substantial firms. The two smaller of these three firms have roughly equal shares, while the third firm is much larger. The table also reveals specific relationships between operators and service companies. Operators II, III, and IV exclusively use one service company. Operator I uses multiple service companies, and also has wells that do not report a service company (and may have been vertically integrated).

Table 3 explores the relation between firm identities, withheld additives - 'trade secrets' - and toxicity of additives. We find significant differences in how different firms employ both trade secret provisions and toxic additives. While there are large differences across service companies and across operators, it is not clear from table 3 whether operator or service company is making the decision not to disclose particular additives. There is a motive for the service company (the seller in this relation) to obscure the mix used in the frac job, so as to enhance its market power (Carlton and Perloff, 2008); this observation suggests it is the service company, and not the operator, which is electing to withhold some ingredients. On the other hand, ultimate responsibility for the well rests with the operator, including liability for environmental consequences, so it may be in their interests to create an air of obfuscation. Under these circumstances it might also be beneficial for the operator to allow the public to think that service companies are keenly interested in protecting trade secrets.

\section{Empirical strategy}

We empirically investigate three dimensions of the fracking process in Sublette County. First, we use the detailed inputs used on different wells to understand the productivity impacts of adjusting the production process. Second, we assess the productivity effects of withheld additives to determine whether such additives can yield higher production. While these results are interesting and policy-relevant, our empirical study does not allow us to assess the net benefits of permitting additives to be withheld from public scrutiny. Third, we use our measures of toxicity of various additives to perform a similar analysis of how more toxic recipes are correlated with production. Like the secrecy analysis, these results do not provide the net benefits from permitting toxic additives to 
be injected, but do document the gains to be had from including some additives that can be toxic. Throughout each of these analyses, we are interested in the relationship between operating firms and their service company partners. The roles of these partners in enhancing productivity, determining which additives are used, and which are not disclosed helps shed light on how the industry has deployed technology to unlock the potential of unconventional resources.

\subsection{Production outcomes}

Our initial empirical specification is a cross-sectional analysis of aggregate production measure during the initial 6 or 12 months of a well's life, based on equation (1):

$$
\ln y_{j}=\beta_{0}+\beta_{1} \mathrm{WATER}_{j}+\beta_{2} \mathrm{SANDRATIO}_{j}+\sum_{i} \alpha_{i} \ln X_{i}+\sum_{k} \gamma_{k} D_{k j}+\varepsilon_{j}
$$

where $D_{k j}$ is an indicator variable equaling 1 if well $j$ was completed in year $2010+k$, for $k=1,2,3$. We use the log of the volume of total base fluid injected as the basis for $W A T E R_{j}$. For every well we also know the location, service company, and the operator at the time of the completion. We also include the relative importance of different classes of additives as described in tables 1 and 2 .

Because we have data on monthly production at each well, we also estimate a wellmonth panel specification,

$$
\ln y_{j t}=\gamma \mathrm{AGE}_{j t}+\beta^{\prime} A_{j}+\sum_{i} \alpha_{i} \ln X_{i}+\varepsilon_{j t}
$$

The variable $\mathrm{AGE}_{j t}$ measures the number of months well $j$ has been actively producing as of time $t$. Accordingly, the parameter $\gamma$ can be interpreted as the average monthly decline rate in production. To the extent that characteristics of the frac job affect the decline rate, interacting those measures with $\mathrm{AGE}_{i t}$ will provide inference about the dynamic effects.

\subsection{Trade secrets and undisclosed additives}

Beyond the basic specifications relating frac designs to production, we examine the impact of undisclosed additives. These regressions identify broad trends in the employment of trade secret provisions to avoid disclosure. We are especially interested in how different operators and service companies might differentially employ these tactics. We begin by estimating the production effects of withheld additives directly.

$$
\ln y_{j t}=\beta^{\prime} A_{j}+\sum_{i} \alpha_{i} \ln X_{i} \times \operatorname{SECRET}_{i}+\varepsilon_{j}
$$

The interpretation of the $\alpha_{i}$ in this specification is as in weighted least squares, with categorical withheld additive counts as weights. We augment those results with an analysis of the total incidence of withheld additives.

$$
\sum \operatorname{SECRET}_{i}=f\left(A_{i}, \mathrm{OPERATOR}_{i}, \mathrm{SERVICE}_{i}, \mathrm{YEAR}_{i}\right)
$$


Because the dependent variable is a non-negative integer, a count model is appropriate for this analysis; we use a negative binomial model. ${ }^{14}$

\subsection{Toxicity}

The third dimension of frac jobs that we investigate is the role of toxic additives. Because it is hard to measure toxicity directly, we interact the aggregate toxicity in each additive class with the amount.

$$
y_{j t}=\beta^{\prime} A_{j}+\sum_{i} \alpha_{i} \ln X_{i} \times \mathrm{TOXIC}_{i}+\varepsilon_{j t} .
$$

The interpretation of the $\alpha_{i}$ in this specification is as weighted least squares, with the categorical toxic additive counts as weights.

We also perform a count analysis of toxic additives similar to the count analysis for trade secrets.

$$
\sum \text { TOXIC }_{i}=f\left(A_{i}, \text { OPERATOR }_{i}, \text { SERVICE }_{i}, \mathrm{YEAR}_{i}\right)
$$

Note that because the toxicity of withheld additives cannot be assessed, we are not able to consider interactions between secrecy and toxicity.

\section{Empirical results}

We now discuss our empirical analysis. We start with a brief discussion of the basic specification, equation (2), focusing on regression results based on the amount of natural gas produced in the first 6 or 12 months of production per thousand feet of treated interval. We find evidence of significant increases in production over time, which can be taken as evidence of learning about the technology - although these gains are not monotonic over time: there appears to be a peak in 2012; this could be attributable to depletion of high-production well locations within the county. We also find evidence of mean differences between operators and service companies, as well as spatial variation in production throughout the county. These results are broadly consistent with prior work. ${ }^{15}$

Because natural gas production extends over a period of time, adjusting the frac job to improve production over time may provide greater returns than other efforts at product differentiation. Table 4 presents results of panel regressions along the lines of equation (3), where we also control for the number of stages and the ratio of sand to water and the total volume of water. ${ }^{16}$ We find evidence of steep decline rates -7.5 per cent per month - over the short period of observed production. This is consistent with previously estimated decline rates in Wyoming (Mason and Roberts, 2018). There is not much

\footnotetext{
${ }^{14} \mathrm{We}$ also estimate Poisson and ordinary least squares (OLS) specifications; these results are relegated to the online appendix.

${ }^{15}$ The regression results are included in tables A6 and A7 (online appendix). Intertemporal effects are evidenced in column 3, differences across firms are indicated in columns 4 and 5, and we allow for spatial effects in column 6.

${ }^{16}$ The number of stages and the water/sand ratio are crucial decision variables for the well completion. We report direct estimates of equation (3) in table A8 in the online appendix. While the coefficients on each additive are individually statistically insignificant, the joint hypothesis that the coefficients on all additives are insignificant can be rejected. All together, we find limited evidence of greater toxicity significantly enhancing production, except for perhaps through friction reducers.
} 
Table 4. Panel results, log monthly gas production

\begin{tabular}{|c|c|c|c|c|}
\hline & (1) & (2) & (3) & (4) \\
\hline Well age & $\begin{array}{c}-0.075^{\star \star} \\
(0.010)\end{array}$ & $\begin{array}{c}-0.076^{\star \star} \\
(0.011)\end{array}$ & $\begin{array}{c}-0.076^{\star \star} \\
(0.011)\end{array}$ & $\begin{array}{c}-0.076^{\star \star} \\
(0.011)\end{array}$ \\
\hline Log water volume (gal) & $\begin{array}{c}0.27^{\star \star \star} \\
(0.0083)\end{array}$ & $\begin{array}{l}0.50^{\star \star \star} \\
(0.011)\end{array}$ & $\begin{array}{l}0.33^{\star \star \star} \\
(0.020)\end{array}$ & $\begin{array}{l}0.28^{\star \star \star} \\
(0.021)\end{array}$ \\
\hline Sand/water ratio & $\begin{array}{l}0.44^{\star \star \star} \\
(0.027)\end{array}$ & $\begin{array}{l}0.52^{\star \star \star} \\
(0.049)\end{array}$ & $\begin{array}{r}-0.24 \\
(0.34)\end{array}$ & $\begin{array}{c}0.30^{\star *} \\
(0.032)\end{array}$ \\
\hline Log treated interval & $\begin{array}{r}-0.055^{\star \star} \\
(0.0099)\end{array}$ & $\begin{array}{c}-0.020 \\
(0.022)\end{array}$ & $\begin{array}{r}-0.083 \\
(0.032)\end{array}$ & $\begin{array}{r}-0.0094 \\
(0.0069)\end{array}$ \\
\hline Stages & $\begin{array}{c}0.038^{\star \star \star} \\
(0.00084)\end{array}$ & $\begin{array}{l}0.027^{\star \star \star} \\
(0.0024)\end{array}$ & $\begin{array}{l}0.046^{\star \star \star} \\
(0.0014)\end{array}$ & $\begin{array}{l}0.040^{\star \star *} \\
(0.0012)\end{array}$ \\
\hline Additive & & $\begin{array}{c}0.12^{\star *} \\
(0.017)\end{array}$ & & \\
\hline Breaker & & $\begin{array}{c}0.11^{\star \star} \\
(0.017)\end{array}$ & & \\
\hline Unspecified & & $\begin{array}{l}0.052^{\star \star \star} \\
(0.0025)\end{array}$ & & \\
\hline Additive $\times$ Toxicity & & & $\begin{array}{c}0.0046 \\
(0.0044)\end{array}$ & \\
\hline Breaker $\times$ Toxicity & & & $\begin{array}{r}-0.0076 \\
(0.0035)\end{array}$ & \\
\hline Unspecified $\times$ Toxicity & & & $\begin{array}{r}-0.036 \\
(0.017)\end{array}$ & \\
\hline Breaker $\times$ Secret & & & & $\begin{array}{r}-0.0049^{*} \\
(0.0015)\end{array}$ \\
\hline Unspecified $\times$ Secret & & & & $\begin{array}{r}-0.0020 \\
(0.0016)\end{array}$ \\
\hline Constant & $\begin{array}{l}6.97^{\star \star \star} \\
(0.18)\end{array}$ & $\begin{array}{l}5.69^{\star \star \star} \\
(0.14)\end{array}$ & $\begin{array}{l}6.34^{\star \star \star} \\
(0.39)\end{array}$ & $\begin{array}{l}6.44^{\star \star \star} \\
(0.39)\end{array}$ \\
\hline Observations & 1868 & 1664 & 1664 & 1664 \\
\hline$R^{2}$ & 0.35 & 0.37 & 0.35 & 0.35 \\
\hline
\end{tabular}

Notes: Dependent variable is the log of monthly gas production. Operator clustered standard errors in parentheses. Significance: ${ }^{\star * \star} p<0.01,{ }^{\star \star} p<0.05,{ }^{\star} p<0.1$.

evidence that decline rates are directly affected by fluid additives as we measure them. Nor do toxicity or trade secrets have a lot of purchase in these specifications.

We next investigate whether withheld or toxic ingredients exhibit important productivity effects; results are reported in table 5 . We focus here on the first six months of production; alternative measures are evaluated in tables A9 and A10 in the online appendix. We allow for idiosyncratic effects from each category of ingredients, along with interaction effects associated with withholding. We include indicator variables for operators I and II, along with the three different service companies; we also include indicator variables for the year the well was completed for 2011-2013 (so 2010 is the excluded year). Accordingly, the estimate associated with a year shows the difference in the average estimated number of withheld ingredients between that year and 2010 - an interesting point of comparison, as Wyoming's reporting regulation took effect in 2010. The results 
Table 5. Trade secret and toxicity results

\begin{tabular}{|c|c|c|c|}
\hline & (1) & (2) & (3) \\
\hline Log water volume & $\begin{array}{c}0.24^{\star} \\
(0.14)\end{array}$ & $\begin{array}{c}0.13 \\
(0.097)\end{array}$ & $\begin{array}{c}0.042 \\
(0.11)\end{array}$ \\
\hline Sand/water ratio & $\begin{array}{r}-1.40^{\star} \\
(0.82)\end{array}$ & $\begin{array}{r}-1.08 \\
(0.81)\end{array}$ & $\begin{array}{r}-0.51 \\
(0.90)\end{array}$ \\
\hline Additives & $\begin{array}{c}0.022 \\
(0.038)\end{array}$ & & \\
\hline Biocides & $\begin{array}{c}0.0055 \\
(0.010)\end{array}$ & & \\
\hline Breakers & $\begin{array}{l}0.028^{\star \star} \\
(0.013)\end{array}$ & & \\
\hline Gels & $\begin{array}{c}0.041 \\
(0.10)\end{array}$ & & \\
\hline Slicks & $\begin{array}{r}-0.023 \\
(0.018)\end{array}$ & & \\
\hline Unspecified & $\begin{array}{c}0.029 \\
(0.027)\end{array}$ & & \\
\hline Interaction terms & & Trade secrets & Toxicity \\
\hline$\times$ Additives & & $\begin{array}{c}0.025^{\star} \\
(0.013)\end{array}$ & $\begin{array}{c}0.025^{*} \\
(0.019)\end{array}$ \\
\hline$\times$ Biocides & & $\begin{array}{r}-0.020^{\star *} \\
(0.0090)\end{array}$ & $\begin{array}{r}-0.016^{\star} \\
(0.0092)\end{array}$ \\
\hline$\times$ Breakers & & $\begin{array}{r}-0.014 \\
(0.031)\end{array}$ & $\begin{array}{c}0.034 \\
(0.012)\end{array}$ \\
\hline$\times$ Gels & & $\begin{array}{c}-0.0019 \\
(0.057)\end{array}$ & $\begin{array}{r}-0.009 \\
(0.026)\end{array}$ \\
\hline$\times$ Slicks & & $\begin{array}{r}-0.0040 \\
(0.012)\end{array}$ & $\begin{array}{r}-0.048 \\
(0.035)\end{array}$ \\
\hline$\times$ Unspecified & & $\begin{array}{c}0.023 \\
(0.014)\end{array}$ & $\begin{array}{c}0.030 \\
(0.053)\end{array}$ \\
\hline Constant & $\begin{array}{l}8.29^{\star \star \star} \\
(1.89)\end{array}$ & $\begin{array}{l}9.63^{\star \star \star} \\
(1.49)\end{array}$ & $\begin{array}{l}8.99^{\star \star \star} \\
(1.89)\end{array}$ \\
\hline$R^{2}$ & 0.085 & 0.069 & 0.086 \\
\hline
\end{tabular}

Notes: Dependent variable: natural log of first 6 months' gas production. Number of observations $=298$. Robust standard errors in parentheses. Lower panel reports coefficients for interaction terms between additive type and secrecy (regression 2) or toxicity (regression 3). Significance: ${ }^{\star \star \star} p<0.01,{ }^{\star \star} p<0.05,{ }^{\star} p<0.1$.

do not suggest strong productivity effects associated with either withholding or toxicity: the estimated cofficients are modest and generally statistically insignificant, both for ingredients that are withheld as trade secrets, and ingredients that are toxic.

Our final line of inquiry relates to the number of ingredients used in a frac job. As noted above, we use a negative binomial count model. ${ }^{17}$ Table 6 reports results of two different negative binomial models that address how many different additives are included in frac recipes. Column (1) reports the number of additives withheld as trade

\footnotetext{
${ }^{17}$ Tables A11 and A12 in the online appendix report specification tests for the negative binomial against alternative statistical models.
} 
Table 6. Negative binomial model results: secrecy \& toxicity

\begin{tabular}{|c|c|c|}
\hline & $\begin{array}{c}(1) \\
\text { Secrecy }\end{array}$ & $\begin{array}{c}(2) \\
\text { Toxicity }\end{array}$ \\
\hline Log water volume & $\begin{array}{c}-0.21^{\star \star *} \\
(0.048)\end{array}$ & $\begin{array}{c}-0.24^{\star * \star} \\
(0.058)\end{array}$ \\
\hline Sand/water ratio & $\begin{array}{l}1.21^{\star \star \star} \\
(0.26)\end{array}$ & $\begin{array}{l}3.24^{\star \star \star} \\
(0.55)\end{array}$ \\
\hline Stages & $\begin{array}{l}0.027^{\star \star \star} \\
(0.0071)\end{array}$ & $\begin{array}{c}0.010^{*} \\
(0.0051)\end{array}$ \\
\hline Secret $\times$ Gels & $\begin{array}{l}0.14^{\star \star \star} \\
(0.034)\end{array}$ & $\begin{array}{l}0.96^{\star \star \star} \\
(0.042)\end{array}$ \\
\hline Secret $\times$ Slicks & $\begin{array}{r}-0.46 \\
(0.58)\end{array}$ & $\begin{array}{c}0.073 \\
(0.055)\end{array}$ \\
\hline Secret $\times$ Unspecified & $\begin{array}{l}0.61^{\star \star \star} \\
(0.045)\end{array}$ & $\begin{array}{c}-0.067^{\star \star \star} \\
(0.02)\end{array}$ \\
\hline Operator I & $\begin{array}{r}-1.66 \\
(1.14)\end{array}$ & $\begin{array}{l}0.64^{\star \star \star} \\
(0.13)\end{array}$ \\
\hline Operator II & $\begin{array}{c}0.92 \\
(1.66)\end{array}$ & $\begin{array}{c}0.079 \\
(0.17)\end{array}$ \\
\hline Service Company A & $\begin{array}{l}13.7^{\star \star \star} \\
(0.52)\end{array}$ & $\begin{array}{r}-0.23^{\star} \\
(0.12)\end{array}$ \\
\hline Service Company B & $\begin{array}{l}12.7^{\star \star \star} \\
(2.26)\end{array}$ & $\begin{array}{l}0.61^{\star \star \star} \\
(0.20)\end{array}$ \\
\hline Service Company C & $\begin{array}{l}13.8^{\star \star \star} \\
(0.55)\end{array}$ & $\begin{array}{r}-0.088 \\
(0.061)\end{array}$ \\
\hline 2011 & $\begin{array}{c}-0.080^{\star \star} \\
(0.039)\end{array}$ & $\begin{array}{c}0.091 \\
(0.080)\end{array}$ \\
\hline 2012 & $\begin{array}{c}-1.53^{\star \star \star} \\
(0.48)\end{array}$ & $\begin{array}{l}0.45^{\star \star \star} \\
(0.085)\end{array}$ \\
\hline 2013 & $\begin{array}{r}-0.90^{\star} \\
(0.46)\end{array}$ & $\begin{array}{l}0.44^{\star \star \star} \\
(0.097)\end{array}$ \\
\hline Constant & $\begin{array}{c}-9.79^{\star \star \star} \\
(1.76)\end{array}$ & $\begin{array}{l}4.03^{\star \star \star} \\
(0.83)\end{array}$ \\
\hline Indiv. Hetero. & $\begin{array}{c}-17.5^{\star \star \star} \\
(0.16)\end{array}$ & $\begin{array}{r}-17.5^{\star \star \star} \\
(0.064)\end{array}$ \\
\hline Observations & 297 & 297 \\
\hline
\end{tabular}

Notes: Dependent variable in column (1) is count of all injected additives that are withheld as trade secrets. Dependent variable in column (2) is count of all injected additives that are identified as toxic by OSHA. Point estimates with robust standard errors reported in parentheses. Significance: ${ }^{* \star *} p<0.01,{ }^{\star \star} p<0.05,{ }^{\star} p<0.1$.

secrets as the dependent variable, while column (2) uses the count of the number of toxic additives as a dependent variable. These results point to some broad conclusions.

First, we note that frac jobs that use more water tend to include fewer additives that are toxic, suggesting that there may be gross substitution between these inputs. This correlation hints at environmental implications: because smaller volumes of water are correlated with more toxic additives, these toxic additives are likely to be relatively more concentrated in the event they come into contact with the broader environment. This 
result takes on added significance in light of the multiple demands on water in the basin: Sublette County is an agricultural region that contains the headwaters of the Green River, a major tributary to the Colorado River, which is an important river system for the western United States. Substituting the demand for water may be offset with potentially more toxic frac recipes. Similar concerns may arise for water-stressed basins in developing countries; this seems likely to apply, for example, in the Vaca Muerta basin of Argentina.

Second, wells using a higher sand/water ratio tend to contain more toxic ingredients. A key use of the various ingredients in a frac job is to facilitate the transit of the proppant into fissures in the host rock; evidently, the companies in our sample preferred relatively more toxic ingredients for this task.

Third, increases in the number of ingredients in the gel or slicks categories tend to increase toxicity, while increases in the number of ingredients in the unspecified category tend to decrease toxicity. While these effects are statistically important, they are not large in magnitude, calling their economic significance into question.

The fourth set of results we obtain are related to the firms involved in the wells. We observe that operator I is associated with significantly greater use of toxics, while operator II is not; in both cases, the comparison is against III and IV. The conclusion we draw is that operator I exhibits a greater tendency to use toxic ingredients than do its rivals. Among the service companies, we see that service company B is associated with more toxic ingredients than either service company A or C. These differences are both statistically and economically important - so we infer that firms differ in important ways.

Fifth, the number of toxics associated with wells completed in 2012 and 2013 is significantly larger than wells completed in 2010; there is no difference between wells completed in 2011 and 2010. This observation casts doubt on the view that the regulation enacted in 2010 induced firms to become more cautious about using toxic ingredients in their wells. ${ }^{18}$

\section{Discussion}

The location of the unconventional natural gas revolution is attributable to myriad factors (Hefner, 2014), including the competitive structure of the US and Canadian oil and gas sectors. It has also been argued that property rights are important, as private ownership of minerals is pervasive in the US (though less so in Canada). Many developing countries have neither a competitive market structure nor well-defined property rights. ${ }^{19}$

Empirical work showing that national oil companies, which are prevalent in developing countries such as Argentina, are less nimble than their shareholder-owned peers often assumes that technology is the same across firm types in order to identify differences in investment incentives (Eller et al., 2011). It has also been argued that technological leadership primarily is associated with international oil companies and some partially privatized national oil companies (Hartley and Medlock III, 2013), though

\footnotetext{
${ }^{18}$ This view was expressed by the governor of the state of Wyoming not long after the regulation was enacted. Of course, it is possible that the regulation induced a decrease over time in the tendency to withhold ingredients, with some of the associated increase in reporting mapping into an increase in the number of reported toxic ingredients. When we estimate similar specifications substituting the number of withheld additives for the number of toxic additives, we find a strong downward trend in the number of trade secrets over time.

${ }^{19}$ As Mares (2014b) notes, every such country 'owns subsoil resources and has the responsibility to set the parameters within which exploitation of these resources will occur in order to benefit the nation.'
} 
there is evidence of convergence in technological abilities over time. HF would seem to be an area for greater convergence.

One particular application of our analysis that seems likely to bear fruit is in Argentina, which possesses significant tight gas reserves. The Vaca Muerta deposit, in particular, has drawn considerable attention. Figure A3 in the online appendix shows well completions, by month, over the past eight years. Here we compare frac operations in the Vaca Muerta against completions in Sublette County - the geographic area that formed the basis of our empirical analysis. ${ }^{20}$ The parallels are readily apparent: over that period, and particularly in the last few years, drilling activity in the Vaca Muerta has proceeded at a similar pace to that in Sublette County, despite its far greater size. In addition, the industrial structures are similar: as in Sublette County, only a handful of companies operate in the Vaca Muerta.

On the other hand, the geology in Wyoming differs from that of western Argentina. In addition, a large fraction of US electricity has historically been generated from coal, which allowed for significant opportunities to lower $\mathrm{CO}_{2}$ emissions as natural gas production ramped up in such places as Wyoming; by contrast, Argentina generates very little electricity from coal. As such, any climate benefits from increased Argentinian natural gas production will either arise from substituting natural gas for fuel oil, which has a lower carbon footprint than coal, or by exporting natural gas to other countries. Indeed, such exports have become increasingly important in the last few years. ${ }^{21}$ This pattern, together with the emerging role for exported LNG, points to the potential for this newly expanded production to impact international markets (EIA, 2019). That said, it is worth remembering that such exports entail significant transactions costs; those additional costs reduce the potential increase in net benefits.

Drawing from our empirical results, there are three lessons for developing countries as they contemplate how to increase indigenous natural gas development through adoption of HF. First, understanding that the technology evolves over time through experimentation and with substantial intellectual property inputs can help foster understanding of how HF fits in a broader context of development. The policy implication of this finding is that firms bringing technical proficiency to the developing world require certain protections of their trade secrets. This is true for operating and servicing firms.

Second, in addition to legal protections required (Andrews-Speed and Christopher, 2014; Chapman et al., 2016) for international firms, the treatment of toxic substances that are integral to increasing productivity in HF must be considered as part of the technology adoption process. Because many toxic injectants are related to increasing the size and productivity of frac jobs, the legal framework allowing for intellectual property retention needs to include this environmental sphere as well. However, we find that toxicity is negatively correlated with water volumes, there may be a tradeoff to furnishing greater supplies of water to avoid toxic additives.

Third, multiple tenders may be desirable, rather than trying to select a single partner ex ante. Our results indicate that firms differ and interact in potentially strategic

\footnotetext{
${ }^{20}$ Drilling data for the Vaca Muerta can be downloaded from http://datos.minem.gob.ar/dataset/ produccion-de-petroleo-y-gas-tablas-dinamicas.

${ }^{21}$ Data from the Argentinian Secretaría de Energía indicates that the average monthly production in 2018-2019 was nearly double that of the preceding three years (1.502 billion cubic feet versus 0.812 billion cubic feet). At the same time, average monthly exports to Chile, Uruguay and Brazil, via pipeline, more than tripled ( 0.534 billion cubic feet versus 0.168 billion cubic feet).
} 
ways. Some rely more on trade secret provisions, others less. It is difficult to know which strategy will dominate before development begins.

\section{Conclusion}

In the past 15 years, innovations in $\mathrm{HF}$ and horizontal drilling have fueled a boom in the production of natural gas and oil from geological formations - primarily deep shales in which hydrocarbon production was previously unprofitable. ${ }^{22}$ Given the widespread endowment of similar resources in developing countries, understanding where the productivity gains of HF come from is central to promoting diffusion of the technology. The economic and environmental benefits of increasing adoption of natural gas in developing countries are substantial.

Although HF has the potential to deliver significant benefits (Mason et al., 2015; Hausman and Kellogg, 2016), it has also raised concerns related to land use footprint, large scale water usage, possible water contamination, wastewater disposal, air emissions and sound pollution (Gomes and Brandt, 2016). These adverse effects have contributed to public opposition to HF, and a number of countries have taken a skeptical view of this technology, including Bulgaria, France, Germany, Ireland and New Zealand (Evensen, 2018). Much of this angst is related to the perception that groundwater is at risk from contamination by the chemicals used as injectants during the fracking process. While a detailed comparison of the potential benefits and costs of HF is beyond the scope of this paper, we are able to highlight some important effects.

Using a unique dataset that combines information on the injectants used in frac jobs, together with information on the production from these wells and the toxicity of the ingredients, we obtain estimates of the nature of various ingredients in the production function for natural gas extracted from these wells. Our results indicate that the marginal product of injecting is largest for crosslinkers and breakers as well as a catch-all residual category.

We find an important correlation between the toxicity of reported injectants and the number of injectants whose identity is withheld under the 'trade secrets' provision. This underscores the intellectual property that firms perceive in their specific application of $\mathrm{HF}$, and has implications for technological diffusion. In addition, our results suggest a trend towards increasing toxicity over time towards the end of our sample. We also document how different firms take alternative approaches to these issues; in particular, we find that one operator (Operator I) and one service company (Service Company B) are more inclined than others to report using toxic additives.

Developing countries have abundant deposits of natural gas that may help address economic, climate and energy policy goals. But care must be paid to the institutional environment that countries create to ensure that the dynamic technology can adapt to the specifics of each country's geology and infrastructure, while recognizing local citizens' concerns about potential adverse effects from HF. Our empirical results provide some guidance along these dimensions and the tradeoffs that policymakers will have to consider. In particular, policymakers would be well-advised to consider both intellectual property considerations, in the form of trade secrets, and environmental regulation of toxic substances in crafting thoughtful regulations.

\footnotetext{
${ }^{22}$ Our empirical application is not in a shale province, but rather in western tight sands that display some similar geological properties.
} 
Supplementary Material. The supplementary material for this article can be found at https://doi.org/10. 1017/S1355770X20000534.

Acknowledgements. The authors thank Gavin Roberts and Colt Van Eaton for excellent research assistance. Thanks are also due to two anonymous referees and Simone Borghesi, each of whom provided constructive criticism that helped sharpen our presentation.

\section{References}

Andrews-Speed P and Christopher L (2014) The legal and commercial determinants of unconventional gas production in East Asia. The Journal of World Energy Law \& Business 7, 408-422.

Bocora J (2012) Global prospects for the development of unconventional gas. Procedia-Social and Behavioral Sciences 65, 436-442.

BP (2019) BP Statistical Review of World Energy. London: BP.

Carlton DW and Perloff JM (2008) Modern Industrial Organization. Boston: Addison Wesley.

Chapman G, Wait R and Kleynhans E (2016) The governance of shale gas production in South Africa. South African Journal of International Affairs 23, 69-88.

Costie DP, Holm F and Berardo R (2018) Hydraulic fracturing, coalition activity and shock: assessing the potential for coalition-based collective action in Argentina's Vaca Muerta formation. The Extractive Industries and Society 5, 499-507.

Covert TR (2014) Experiential and social learning in firms: the case of hydraulic fracturing in the Bakken shale. University of Chicago Working Paper. Available at https://home.uchicago.edu/ tcovert/webfiles/ fracking.pdf.

Dora M (2014) The energy sector and the governance of unconventional fuels in Brazil. Oil, Gas \& Energy Law Intelligence 12, 1-20.

EIA (2019) Growth in Argentina's Vaca Muerta shale and tight gas production leads to LNG exports. U.S. Energy Information Administration. Available at http://www.eia.gov/todayinenergy/detail.php? id $\{\backslash$ mathsurround $=$ lopskip $\$=\$\} 40093 \#$.

Eller SL, Hartley PR, Medlock III KB (2011) Empirical evidence on the operational efficiency of national oil companies. Empirical Economics 40, 623-643.

EPA (Environmental Protection Agency) (2015) Analysis of Hydraulic Fracturing Fluid Data from the FracFocus Chemical Disclosure Registry 1.0. Washington, DC: GPO.

Evensen D (2018) Yet more fracking' social science: an overview of unconventional hydrocarbon development globally. The Extractive Industries and Society 5, 417-421.

Fell $\mathbf{H}$ and Kaffine DT (2018) The fall of coal: joint impacts of fuel prices and renewables on generation and emissions. American Economic Journal: Economic Policy 10, 90-116.

Fetter TR, Steck AL, Timmins C and Wrenn D (2018) Learning by viewing? Social learning, regulatory disclosure, and firm productivity in shale gas. NBER Working Paper 25401, National Bureau of Economic Research, Cambridge, MA.

Florencia SM (2018) Argentina. Energy extraction and communities: Can shale development proceed without causing pollution and conflicts?. In Gamper-Rabindran S (ed.), The Shale Dilemma: A Global Perspective on Fracking and Shale Development. Pittsburgh, PA: University of Pittsburgh Press, pp. 305-341.

Gamper-Rabindran S (2018) Introduction. The shale dilemma. In Gamper-Rabindran S (ed.), The Shale Dilemma: A Global Perspective on Fracking and Shale Development. Pittsburgh, PA: University of Pittsburgh Press, pp. 3-30.

Gold R (2014) The Boom: How Fracking Ignited the American Energy Revolution and Changed the World. New York: Simon and Schuster Paperbacks.

Gomes I and Brandt R (2016) Unconventional gas in Argentina: will it become a game changer? OIES Working Paper NG 113. Oxford Institute for Energy Studies, Oxford, UK.

Hartley PR and Medlock III KB (2013) Changes in the operational efficiency of national oil companies. The Energy Journal 34, 27-57.

Hausman C and Kellogg R (2016) Welfare and distributional implications of shale gas. Brookings Papers on Economic Activity 2015, 71-139.

Hefner III RA (2014) The United States of gas. Foreign Affairs 93, 9-14. 
Hull R (2014) A play for shale: expanding resources in the European Union. International Shale Gas and Oil Journal 4, 9-16.

Jacoby HD, O'Sullivan FM and Paltsev S (2012) The influence of shale gas on U.S. energy and environmental policy. Economics of Energy \& Environmental Policy 1, 37-51.

Kahrilas GA, Blotevogel J, Stewart PS and Borch T (2014) Biocides in hydraulic fracturing fluids: a critical review of their usage, mobility, degradation, and toxicity. Environmental Science \& Technology 49, 16-32.

Lin A (2018) China.Replacing coal with shale gas: could reducing China's regional air pollution lead to more local pollution in rural China? In Gamper-Rabindran S eds, The Shale Dilemma: A Global Perspective on Fracking and Shale Development. Pittsburgh, PA: University of Pittsburgh Press, pp. 267-304.

Mares D (2012) The new energy landscape: shale gas in Latin America. Discussion Paper IDB-DP-253, Inter-American Development Bank, Washington DC.

Mares D (2013) Political economy of shale gas in Argentina. Discussion Paper, James A. Baker III Institute for Public Policy of Rice University, Houston, TX.

Mares D (2014a) Argentine shale gas development - on track? International Shale Gas and Oil Journal 4, $29-32$.

Mares D (2014b) The governance of shale gas in Argentina. Oil, Gas \& Energy Law Intelligence 12, 1-18.

Mares D (2014c) Kick-starting the shale boom in Argentina? The new reforms in context. Oxford Energy Forum 98, 16-18.

Mason CF and Roberts G (2018) Price elasticity of supply and productivity: an analysis of natural gas wells in Wyoming. The Energy Journal 39, 79-100.

Mason CF, Muehlenbachs LA and Olmstead SM (2015) The economics of shale gas development. Annual Review of Resource Economics 7, 269-289.

Morkel B and de Witt M (2018) South Africa. Trying not to repeat history: are shale gas development and broad-based economic development compatible. In Gamper-Rabindran S eds, The Shale Dilemma: A Global Perspective on Fracking and Shale Development. Pittsburgh, PA: University of Pittsburgh Press, pp. 341-378.

Oliver M, Mason CF and Finnoff D (2014) Pipeline congestion and natural gas basis differentials: theory and evidence. Journal of Regulatory Economics 46, 261-291.

Patel P, Robart CJ, Ruegamer M and Yang A (2014) Analysis of US hydraulic fracturing fluid system and proppant trends. SPE Hydraulic Fracturing Technology Conference, paper number 168645.

Rogers H (2011) Shale gas - the unfolding story. Oxford Review of Economic Policy 27, 117-143.

Sierra DE (2016) Developing a Vaca Muerta shale play: an economic assessment approach. (Ph.D. thesis). University of Texas, Austin, TX.

Sinn H-W (2017) Buffering volatility: a study on the limits of Germany's energy revolution. European Economic Review 99, 130-150.

Stringfellow WT, Domen JK, Camarillo MK, Sandelin WL and Borglin S (2014) Physical, chemical, and biological characteristics of compounds used in hydraulic fracturing. Journal of Hazardous Materials 275, 37-54.

Wang H, Ma F, Tong X, Liu Z, Zhang X, Wu Z, Li D, Wang B, Xie Y and Yang L (2016) Assessment of global unconventional oil and gas resources. Petroleum Exploration and Development 43, 925-940.

Weijermars R, Drijkoningen G, Heimovaara TJ, Rudolph ESJ, Weltje GJ and Wolf KHAA (2011) Unconventional gas research initiative for clean energy transition in Europe. Journal of Natural Gas Science and Engineering 3, 402-412.

Yergin D (2011) The Quest: Energy, Security, and the Remaking of the Modern World. New York, NY: Penguin.

Cite this article: Fitzgerald T, Mason CF (2021). Understanding productivity effects of hydraulic fracturing in unconventional natural gas deposits and implications for adoption in the developing world. Environment and Development Economics 26, 281-301. https://doi.org/10.1017/S1355770X20000534 